\title{
Coordinating Contracts for Two-Stage Fashion Supply Chain with Risk-Averse Retailer and Price-Dependent Demand
}

\author{
Minli Xu, ${ }^{1}$ Qiao Wang, ${ }^{1}$ and Linhan Ouyang ${ }^{2}$ \\ ${ }^{1}$ School of Business, Central South University, Changsha 410083, China \\ ${ }^{2}$ School of Management, Nanjing University of Science and Technology, Nanjing 210094, China \\ Correspondence should be addressed to Minli Xu; xu_minli@163.com
}

Received 7 December 2012; Accepted 11 January 2013

Academic Editor: Tsan-Ming Choi

Copyright (c) 2013 Minli Xu et al. This is an open access article distributed under the Creative Commons Attribution License, which permits unrestricted use, distribution, and reproduction in any medium, provided the original work is properly cited.

\begin{abstract}
When the demand is sensitive to retail price, revenue sharing contract and two-part tariff contract have been shown to be able to coordinate supply chains with risk neutral agents. We extend the previous studies to consider a risk-averse retailer in a two-echelon fashion supply chain. Based on the classic mean-variance approach in finance, the issue of channel coordination in a fashion supply chain with risk-averse retailer and price-dependent demand is investigated. We propose both single contracts and joint contracts to achieve supply chain coordination. We find that the coordinating revenue sharing contract and two-part tariff contract in the supply chain with risk neutral agents are still useful to coordinate the supply chain taking into account the degree of risk aversion of fashion retailer, whereas a more complex sales rebate and penalty (SRP) contract fails to do so. When using combined contracts to coordinate the supply chain, we demonstrate that only revenue sharing with two-part tariff contract can coordinate the fashion supply chain. The optimal conditions for contract parameters to achieve channel coordination are determined. Numerical analysis is presented to supplement the results and more insights are gained.
\end{abstract}

\section{Introduction}

Fashion supply chain is characterized by short product life cycle, high volatile customer demand, and clients' varying tastes [1]. Within such supply chains, it is difficult to predict the demand accurately. Because of the highly demand uncertainty, the fashion retailer must suffer risks from the trading off between overstocks and stock-outs [2]. Besides, the complex features of fashion supply chain make supply chain coordination increasingly significant for supply chain agents in fashion industry.

Coordination among supply chain agents via setting incentive alignment contracts is a hot topic in supply chain management. Under the coordinating contracts, the incentives of supply chain agents are aligned with the objective of the whole supply chain so that the decentralized supply chain behaves as well as the vertically integrated supply chain. Without supply chain coordination, problems involving double marginalization will prevail [3], reducing the supply chain's efficiency tremendously. Over the past two decades, many forms of contracts with reasonable contract parameters have been studied to achieve supply chain coordination with risk-neutral agents by fighting against the issue of double marginalization. These traditional contracts include returns policy $[4,5]$, revenue-sharing contract [6], quantity flexibility contract $[7,8]$, two-part tariff contract [9], and sales rebate contract [10-13]. For more detailed information of papers on these and some other supply chain contracts, please refer to [14].

Revenue-sharing contract indicates that the newsvendor retailer pays the upstream manufacturer a unit wholesale price for each unit ordered plus a proportion of his revenue from selling the product. Both theoretical and empirical studies have been carried out on the effect of revenue-sharing contract in the video cassette rental industry $[15,16]$. Under the classic newsvendor models, such contracts have been shown to be capable of coordinating the newsvendor $[6,17$, $18]$.

Under a two-part tariff contract, the retailer gives the manufacturer a fixed transfer payment apart from the unit 
wholesale price for each unit purchased. And it has also been shown that a two-part tariff contract coordinates the supply chain, when the optimal value of unit wholesale price equals the manufacturer's unit production cost [9].

Sales rebate and penalty (SRP) is based on the retailer's sales performance. With a SRP contract, the manufacturer will specify a certain sales target prior to the selling season. Different from sales rebate which executes rebate only, for each unit sold above the target level, the retailer will be granted a unit rebate, or else the retailer must pay the manufacturer a penalty. In supply chain management, both SRP contract and sales rebate contract have been demonstrated unable to coordinate the channel when the demand is sensitive to retail price or the retailer's sales effort [10, 19-21].

Early studies considered retail price exogenous, leaving the retailer with the decision of order quantity alone in order to maximize expected profit. As retail price plays an important role in marketing channel, a new steam of research on supply chain coordination and contracting integrates pricing into the order quantity decision of the retailer under different demand models. Reviews of this work [12, 22] explicitly stated that revenue-sharing contract and two-part tariff contract are able to coordinate the newsvendor with price-dependent demand, while many other traditional contracts aren't. And there is an increasing interest in examining combined contracts consisting of two or more traditional contracts to achieve channel coordination [19-21,23].

However, the common results derived from the previous studies may not be precise in operations management since, in the real world, different decision makers may have different degrees of risk aversion. in light of this, we extend the results of proceeding studies to explore the issue of supply chain coordination with risk-averse fashion retailer and price-dependent demand. Specifically, we investigate a single period, one-manufacturer one-retailer fashion supply chain with a variety of contracts. The manufacturer, acting as the leader in the Stackelberg game, offers the retailer a contract with a set of contract parameters. The fashion retailer, acting as the follower, sets self-interest order quantity and retail price as a response. We propose both single contracts and combined contracts with the optimal values of contract parameters to achieve channel coordination within fashion supply chain.

The main objectives of our study cover the following: firstly, to explore whether the coordinating revenue-sharing contract and two-part tariff contract in supply chains with risk neural retailer can still coordinate the fashion supply chain with risk-averse retailer who has to choose retail price in addition to stocking quantity; secondly, to compare the performance of a more complicated sales rebate and penalty contract in supply chain coordination with the performances of revenue-sharing contract and two-part tariff contract; finally, when joint contracts are got by taking advantages of the three single contracts, to probe whether the resulting combined contracts are useful to coordinate the supply chain.

In recent years, an increasing number of researchers have noticed the importance and the impact of risk aversion in supply chain contracting and coordination and sought in succession for the criteria to depict supply chain agents' risk aversion attitude or preference. In the literature, the measures for describing risk aversion involve meanvariance (MV) [24], Neumann-Morgenstern utility function (VNUM), mean-downside-risk (MDR) [25], Value-at-risk (VaR) $[26,27]$, and Conditional Value-at-risk (CVaR) [28, 29]. Since MV is simple, implementable and is easily understood by managers and practitioners compared with other measures, we adopt mean-variance formulation to capture the fashion retailer's risk aversion in this paper.

This paper is closely linked to the literature on supply chain coordinating and contracting with price-dependent demand $[30,31]$ in terms of a random and price-dependent demand. It is also correlated to studies of supply chain coordination with agents having risk preferences in which we consider a risk-averse retailer [32-36]. But our study is the first to investigate the issue of channel coordination for the supply chain with risk-averse retailer and pricedependent demand. We firstly investigate the problem of coordinating a two-stage fashion supply chain under single contracts including revenue-sharing contract, two-part tariff contract and sales rebate and penalty contract. After proving that revenue-sharing contract and two-part tariff contract could still achieve channel coordination in this context while a more complex sales rebate and penalty cannot, we further explore the role of combined contracts (sales rebate and penalty with revenue-sharing contract, sales rebate and penalty with two-part tariff contract, and revenue sharing with two-part tariff contract) in supply chain coordination. By identifying the coordination conditions and mechanisms of various contracts, our work contributes to supplement the current literature on supply chain coordination and contracting. We also provide meaningful guidance to managers in real operations management on how to choose the type of contract and determine the optimal contract parameters in order to coordinate fashion supply chain in more complicated newsvendor frameworks.

The paper is organized as follows. Model formulation and notation definition are presented in Section 2. The benchmark case of integrated fashion supply chain is studied in Section 3. Supply chain coordination under single contracts and combined contracts is investigated in Sections 4 and 5. Numerical study to supplement the analytical results and gain more insights is given in Section 6. Section 7 provides managerial insights and concluding comments.

\section{Model Formulation and Notation Definition}

Consider a two-echelon fashion supply chain with a riskneutral manufacturer and a risk-averse retailer. The retailer sells a fashion product whose demand is sensitive to retail price. The upstream manufacturer produces the product and sells it through a vertically separated retailer. The sequence of events in the supply chain is as follows. The manufacturer, as the leader of a Stackelberg game, offers the retailer a contract. After knowing the details of the contract, the fashion retailer commits his order quantity and retail price. Then the manufacturer organizes the production and delivers the finished products to the retailer prior to the selling season. Afterwards, the selling season starts, and the demand is 
realized. At the end of the selling season, based on the agreed contract, both the manufacturer and the retailer perform the respective contract terms and achieve transfer payments between each other.

Let $p$ be the retail price, $c$ the production cost incurred by the manufacturer, $w(w \geq c)$ the wholesale price, $v(v<c)$ the salvage value of unsold inventory, and $q$ the production/order quantity. Use $t>0$ as the sales target level and $u>0$ as the rebate (and penalty) for sales rebate and penalty contract. Use $\lambda \in(0,1)$ as the fraction of revenue earned by the retailer in revenue-sharing contract and $G>0$ as the fixed transfer payment from the retailer to the manufacturer in two-part tariff contract.

In the literature, there are two fashions in which the demand $x$ depends on the selling price $p$ : (1) the additive form $x=D(p)+\xi$; (2) the multiplicative form $x=D(p) \xi$, where $D(p) \geq 0$ is a function of $p$ representing the expected demand and $\xi$ is a nonnegative variable representing the random proportion of the demand. $\xi$ is independent of selling price $p$ with a probability density function $f(\cdot)$ and a cumulative distribution function $F(\cdot)$. It is assumed that $f(\cdot)>0$ has a continuous derivative $f^{\prime}(\cdot) . F(\cdot)$ is continuous, strictly increasing, and differentiable. Let $F^{-1}(\cdot)$ be the reverse function of $F(\cdot)$, and $\bar{F}(\cdot)=1-F(\cdot) . D(p)$ is strictly decreasing in $p$, and $D^{\prime}(p)<0$. In this paper, we only consider the additive demand model. For the multiplicative one, we believe similar results would be derived.

In order to ensure the existence and uniqueness of model results, we give the following definitions of $D(p)$ and $\xi$.

Definition 1. By definition, $e=-p D^{\prime}(p) / D(p)$ is the price elasticity of $D(p) . D(p)$ has an increasing price elasticity (IPE) in $p$, if

$$
\frac{d e}{d p} \geq 0
$$

Price elasticity $e$ measures the percentage change in demand with respect to one percentage change in selling price. The IPE property is intuitive. In the literature, many demand forms own IPE property, such as the simplest linear demand, isoelastic demand, and exponential demand.

For the ease of position, in this paper, we suppose a linear demand of $D(p)$. Let $D(p)=a-k p$, where $a>0$ is the base demand and $k>0$ is the price elasticity of demand. Thus, we have $p \in[c, a / k]$.

Definition 2. Define $r(\xi)=f(\xi) /(1-F(\xi))$ as the failure rate of the $\xi$ distribution then $\xi$ has an increasing failure rate (IFR), if for $\xi \geq 0$

$$
r^{\prime}(\xi) \geq 0
$$

It is noted that, in the literature, various random distributions exhibit IFR property, involving uniform and normal distributions.
To capture the decision making of risk-averse fashion retailer, we adopt the same risk aversion decision model as in [34]:

$$
\begin{array}{ll}
\min & V_{r}(q, p) \\
\text { s.t. } & E_{r}(q, p) \geq k_{r},
\end{array}
$$

where $E_{r}(q, p)$ and $V_{r}(q, p)$ denote the mean and the variance of the retailer's profit, respectively, and $k_{r}>0$ denotes the retailer's expected profit threshold. $k_{r}$ can be considered to be the indicator of the retailer's risk aversion degree, since larger values of $k_{r}$ indicate that the retailer does not want to earn a low expected profit, leading to a more risk-averse retailer. Define $\bar{E}_{r}=E_{r}\left(q_{r}{ }^{*}, p_{r}{ }^{*}\right)$ as the retailer's attainable maximum expected profit. Then from (P-1), $k_{r} \leq \bar{E}_{r}$ must establish, otherwise, there is no feasible solution for (P-1).

\section{The Integrated Fashion Supply Chain}

First, we offer a benchmark by analyzing the case when the fashion supply chain is vertically integrated so that the manufacturer owns its own retailer. Note that the type of contract does not affect the performance of the integrated fashion supply chain. The optimal solutions to this model are production level $q$ and retail price $p$, which provide us with guidelines to the optimal policy for the whole system. Define $Q=q-D(p), \eta(Q)=2 Q \int_{0}^{Q} F(\xi) d \xi-2 \int_{0}^{Q} \xi F(\xi) d \xi-$ $\left(\int_{0}^{\mathrm{Q}} F(\xi) d \xi\right)^{2}$. The integrated fashion supply chain's profit, expected profit, and the variance of profit are given as follows:

$$
\prod_{\mathrm{sc}}(Q, p)=(p-c) D(p)+(p-c) Q-(p-v)(Q-\xi)^{+},
$$

$$
E_{\mathrm{sc}}(Q, p)=(p-c) D(p)+(p-c) Q-(p-v) \int_{0}^{Q} F(\xi) d \xi
$$

$$
V_{\mathrm{sc}}(Q, p)=(p-v)^{2} \eta(Q)
$$

Let $\left(Q_{\mathrm{sc}}{ }^{*}, p_{\mathrm{sc}}{ }^{*}\right)$ and $q_{\mathrm{sc}}{ }^{*}=D\left(p_{\mathrm{sc}}{ }^{*}\right)+Q_{\mathrm{sc}}{ }^{*}$ be the optimal joint decision and optimal production level for the integrated supply chain.

Proposition 3. Under the additive price-dependent demand, the integrated supply chain's optimal joint decision $\left(Q_{s c}{ }^{*}, p_{s c}{ }^{*}\right)$ and optimal production quantity $q_{s c}{ }^{*}$ exist and are unique, satisfying

$$
\begin{gathered}
\left(p_{\mathrm{sc}}{ }^{*}-c\right)-\left(p_{\mathrm{sc}}{ }^{*}-v\right) F\left(Q_{\mathrm{sc}}{ }^{*}\right)=0, \\
a-k\left(2 p_{\mathrm{sc}}{ }^{*}-c\right)+Q_{\mathrm{sc}}{ }^{*}-\int_{0}^{\mathrm{Q}_{\mathrm{sc}}{ }^{*}} F(\xi) d \xi=0, \\
q_{\mathrm{sc}}{ }^{*}=a-k p_{\mathrm{sc}}{ }^{*}+F^{-1}\left(\frac{p_{\mathrm{sc}}{ }^{*}-c}{p_{\mathrm{sc}}{ }^{*}-v}\right) .
\end{gathered}
$$

Proof. For any given $p \in[c, a / k]$, from (4), by taking the first and second differentials of $E_{\mathrm{sc}}(Q, p)$ with respect to $Q$, we get 
$\partial E_{\mathrm{sc}}(Q, p) / \partial Q=(p-c)-(p-v) F(Q), \partial^{2} E_{\mathrm{sc}}(Q, p) / \partial Q^{2}=$ $-(p-v) f(Q)<0$. Thus, for any given $p \in[c, a / k], E_{\mathrm{sc}}(Q, p)$ is a concave function of $Q$, and $Q_{s c}{ }^{*}$ is finite and unique, satisfying

$$
(p-c)-(p-v) F\left(Q_{s c}{ }^{*}\right)=0 .
$$

From (9), we know that $Q_{\mathrm{sc}}{ }^{*}$ is a function of $p$. According to the implicit function theorem, we have

$$
\frac{d Q_{\mathrm{sc}}{ }^{*}}{d p}=-\frac{\partial^{2} E_{\mathrm{sc}}\left(Q_{\mathrm{sc}}{ }^{*}, p\right) / \partial Q \partial p}{\partial^{2} E_{\mathrm{sc}}\left(Q_{\mathrm{sc}}{ }^{*}, p\right) / \partial Q^{2}}=\frac{1-F\left(Q_{\mathrm{sc}}{ }^{*}\right)}{(p-v) f\left({Q_{\mathrm{sc}}}^{*}\right)}
$$

Therefore, from (10), $Q_{\mathrm{sc}}{ }^{*}$ is strictly increasing in $p$.

By taking $Q_{\mathrm{sc}}{ }^{*}$ into $E_{\mathrm{sc}}(Q, p)$, we get $E_{\mathrm{sc}}\left(Q_{\mathrm{sc}}{ }^{*}, p\right)$. Taking the first and second derivatives of $E_{\mathrm{sc}}\left(Q_{\mathrm{sc}}{ }^{*}, p\right)$ with respect to $p$, we derive:

$$
\begin{gathered}
\frac{d E_{\mathrm{sc}}\left(Q_{\mathrm{sc}}{ }^{*}, p\right)}{d p}=a-k(2 p-c)+Q_{\mathrm{sc}}{ }^{*}-\int_{0}^{\mathrm{Q}_{\mathrm{sc}}{ }^{*}} F(\xi) d \xi \\
\frac{d^{2} E_{\mathrm{sc}}\left(Q_{\mathrm{sc}}{ }^{*}, p\right)}{d p^{2}}=-2 k+\left(1-F\left(Q_{\mathrm{sc}}{ }^{*}\right)\right) \frac{d Q_{\mathrm{sc}}{ }^{*}}{d p}
\end{gathered}
$$

Substituting (10) into (12), we get

$$
\frac{d^{2} E_{\mathrm{sc}}\left(Q_{\mathrm{sc}}{ }^{*}, p\right)}{d p^{2}}=-2 k+\frac{\left(1-F\left(Q_{\mathrm{sc}}{ }^{*}\right)\right)^{2}}{(p-v) f\left(Q_{\mathrm{sc}}{ }^{*}\right)}
$$

Define $H(Q)=f(Q) /(1-F(Q))^{2}$, and taking the derivative of $H(Q)$ with respect to $Q$, we have

$$
\frac{d H(Q)}{d Q}=\frac{(1-F(Q)) f^{\prime}(Q)+2(f(Q))^{2}}{(1-F(Q))^{3}} .
$$

From Definition 2, we know that $H\left(Q_{\mathrm{sc}}{ }^{*}\right)$ is strictly increasing in $p$. Therefore, $d^{2} E_{\mathrm{sc}}\left(Q_{\mathrm{sc}}{ }^{*}, p\right) / d p^{2}$ is strictly decreasing in $p$. Let $p^{0}$ satisfy $d^{2} E_{\mathrm{sc}}\left(Q_{\mathrm{sc}}{ }^{*}, p\right) / d p^{2}=0$. If $p^{0}$ does not exist, then we can know $d^{2} E_{\mathrm{sc}}\left(Q_{\mathrm{sc}}{ }^{*}, p\right) / d p^{2}<0$, since $\lim _{p \rightarrow \infty} d^{2} E_{\mathrm{sc}}\left(Q_{\mathrm{sc}}{ }^{*}, p\right) / d p^{2}=-2 k<0$, and $E_{\mathrm{sc}}\left(Q_{\mathrm{sc}}{ }^{*}, p\right)$ is a concave function of $p$. If $p^{0}$ exists, for $p<p^{0}$, $d^{2} E_{\mathrm{sc}}\left(Q_{\mathrm{sc}}{ }^{*}, p\right) / d p^{2}>0$, and, for $p>p^{0}, \partial^{2} E_{\mathrm{sc}}\left(Q_{\mathrm{sc}}{ }^{*}, p\right) / \partial p^{2}<$ 0 . That is, $E_{\mathrm{sc}}\left(Q_{\mathrm{sc}}{ }^{*}, p\right)$ is convex in $p$ for $p<p^{0}$ and concave in $p$ for $p>p^{0}$. Because $d E_{\mathrm{sc}}\left(Q_{\mathrm{sc}}{ }^{*}, p\right) /\left.d p\right|_{p=c}=(a-$ $k c)+\int_{0}^{\mathrm{Q}^{*}{ }^{*}(c)} \bar{F}(\xi) d \xi>0, E_{\mathrm{sc}}\left(Q_{\mathrm{sc}}{ }^{*}, p, e\right)$ is unimodal in $p \in[c, a / k]$.

Hence, there exists a unique retail price $p_{\mathrm{sc}}{ }^{*} \in[c, a / k]$ that maximizes $E_{\mathrm{sc}}\left(Q_{\mathrm{sc}}{ }^{*}, p\right)$ and is given by (7).

Since $q_{\mathrm{sc}}{ }^{*}=D\left(p_{\mathrm{sc}}{ }^{*}\right)+Q_{\mathrm{sc}}{ }^{*}$, it is natural to conclude that the fashion supply chain's optimal production quantity $q_{\mathrm{sc}}{ }^{*}$ is unique and satisfies (8).

Remark 4. Proposition 3 reveals the optimal solutions of the integrated fashion supply chain with the additive pricedependent demand. Correspondingly, the entire supply chain's maximum expected profit is $\bar{E}_{\mathrm{sc}}=E_{\mathrm{sc}}\left(Q_{\mathrm{sc}}{ }^{*}, p_{\mathrm{sc}}{ }^{*}\right)$.

\section{The Decentralized Fashion Supply Chain under Single Contracts}

Now we consider the case when the fashion supply chain is decentralized. In the decentralized supply chain, the manufacturer and the fashion retailer are independent and enter a Stackelberg game as described before. Specifically, the retailer is assumed to be risk-averse with an expected profit threshold $k_{r}>0$ and $k_{r}<\bar{E}_{\mathrm{sc}}$ (otherwise, there would be no incentive for the manufacturer to offer a contact). As an extension of prior works, in the following sections, we will consider the optimal joint pricing-inventory decisions of a risk-averse retailer in the decentralized fashion supply chain under single contracts such as revenue sharing contact, sales rebate and penalty contract, and two-part tariff contract. For the purpose of simplification, define $Q=q-D(p), T=t-D(p)$ and $T^{*}=t-D\left(p^{*}\right)$. Let $\left(Q_{r}{ }^{*}, p_{r}{ }^{*}\right)$ and $\left(Q_{r, m v}{ }^{*}, p_{r, m v}{ }^{*}\right)$ be the optimal joint decisions for the risk-neutral retailer and riskaverse retailer, respectively.

4.1. SRP Contract. With a SRP contract $\theta_{\mathrm{SRP}}(w, t, u)$, the manufacturer offers a sales target $t>0$ to the retailer prior to the selling season. At the end of the selling season, for each unit sold above $t$, the manufacturer will give the retailer a unit rebate $u>0$, otherwise, the retailer must pay the manufacturer a penalty $u$.

In this setting, the fashion retailer's profit, expected profit and the variance of profit are

$$
\begin{aligned}
\prod_{r}(Q, p) & \\
= & (p-w) D(p)+(p-w) Q-(p-v)(Q-\xi)^{+} \quad(15) \\
& +u(\min (\xi, Q)-T) \\
E_{r}(Q, p) & \\
= & (p-w) D(p)+(p-w) Q-(p-v) \int_{0}^{Q} F(\xi) d \xi \\
& +u\left(Q-T-\int_{0}^{Q} F(\xi) d \xi\right), \\
V_{r}(Q, p) & \\
= & \left(\prod_{r}(Q, p)-E_{r}(Q, p)\right)^{2} \\
= & (p-v)^{2} E\left(\int_{0}^{Q} F(\xi) d \xi-(Q-\xi)^{+}\right)^{2} \\
& +2 u(p-v) E\left(\int_{0}^{Q} F(\xi) d \xi-(Q-\xi)^{+}\right) \\
& +u^{2} E\left((\min (\xi, Q)-T)-\left(Q-T-\int_{0}^{Q} F(\xi) d \xi\right)\right)^{2} \\
& \\
& \\
& \\
& \\
&
\end{aligned}
$$




$$
\begin{gathered}
=(p-v)^{2}\left(\int_{0}^{Q}(Q-\xi)^{2} f(\xi) d \xi-\left(\int_{0}^{Q} F(\xi) d \xi\right)^{2}\right) \\
+u^{2}\left(\int_{0}^{Q}(\xi-T)^{2} f(\xi) d \xi+\int_{Q}^{\infty}(Q-T)^{2} f(\xi) d \xi\right. \\
\left.-\left(Q-T-\int_{0}^{Q} F(\xi) d \xi\right)^{2}\right) \\
+2 u(p-v)\left(\int_{0}^{Q} F(\xi) d \xi\left(Q-T-\int_{0}^{Q} F(\xi) d \xi\right)\right. \\
\left.-\int_{0}^{Q}(Q-\xi)(\xi-T) f(\xi) d \xi\right) \\
=(p-v+u)^{2}\left(2 Q \int_{0}^{Q} F(\xi) d \xi-2 \int_{0}^{Q} \xi F(\xi) d \xi\right. \\
\left.-\left(\int_{0}^{Q} F(\xi) d \xi\right)^{2}\right) \\
=(p-v+u)^{2} \eta(Q) .
\end{gathered}
$$

Proposition 5. For a given SRP contract $\theta_{S R P}(w, t, u)$ offered by the manufacturer, the risk-neutral retailer's optimal joint decision $\left(Q_{r}{ }^{*}, p_{r}{ }^{*}\right)$ is given by

$$
\begin{array}{r}
\left(p_{r}{ }^{*}-w+u\right)-\left(p_{r}{ }^{*}-v+u\right) F\left(Q_{r}{ }^{*}\right)=0, \\
a-k\left(2 p_{r}{ }^{*}-w+u\right)+Q_{r}{ }^{*}-\int_{0}^{Q_{r}{ }^{*}} F(\xi) d \xi=0 .
\end{array}
$$

Proof. For any given $p \in(w-u, \bar{p}]$, from (16), by taking the first and second differentials of $E_{r}(Q, p)$ with respect to $Q$, we can derive that $\partial E_{r}(Q, p) / \partial Q=(p-w+u)-(p-v+u) F(Q)$, and $\partial^{2} E_{r}(Q, p) / \partial Q^{2}=-(p-v+u) f(Q)<0$. Thus, $E_{r}(Q, p)$ is a concave function of $Q$. $Q_{r}{ }^{*}$ can be given by

$$
(p-w+u)-(p-v+u) F\left(Q_{r}{ }^{*}\right)=0 .
$$

From (20), we can get to know that $Q_{r}{ }^{*}$ is a function of $p$. By making use of the implicit function theorem, we have

$$
\frac{d Q_{r}{ }^{*}}{d p}=-\frac{\partial^{2} E_{r}\left(Q_{r}{ }^{*}, p\right) / \partial Q \partial p}{\partial^{2} E_{r}\left(Q_{r}{ }^{*}, p\right) / \partial Q^{2}}=\frac{1-F\left(Q_{r}{ }^{*}\right)}{(p-v+u) f\left(Q_{r}{ }^{*}\right)} .
$$

Thus, we know that $Q_{r}{ }^{*}$ is strictly increasing in $p$. Substituting $Q_{r}{ }^{*}$ into $E_{r}(Q, p)$, we get

$$
\begin{aligned}
& E_{r}\left(Q_{r}{ }^{*}, p\right) \\
& =(p-w) D(p)+(p-w) Q_{r}{ }^{*}-(p-v) \int_{0}^{Q_{r}{ }^{*}} F(\xi) d \xi \\
& \quad+u\left(Q_{r}{ }^{*}-T-\int_{0}^{Q_{r}{ }^{*}} F(\xi) d \xi\right) .
\end{aligned}
$$

From (22), $E_{r}\left(Q_{r}{ }^{*}, p\right)$ can be regarded as a function of variable $p$ alone. Taking the first and second derivatives of $E_{r}\left(Q_{r}{ }^{*}, p\right)$ with respect to $p$, we get

$$
\begin{gathered}
\frac{d E_{r}\left(Q_{r}{ }^{*}, p\right)}{d p}=a-k(2 p-w+u)+Q_{r}{ }^{*}-\int_{0}^{Q_{r}{ }^{*}} F(\xi) d \xi \\
\frac{d^{2} E_{r}\left(Q_{r}{ }^{*}, p\right)}{d p^{2}}=-2 k+\left(1-F\left(Q_{r}{ }^{*}\right)\right) \frac{d Q_{r}{ }^{*}}{d p} .
\end{gathered}
$$

By taking (21) into (24), we have

$$
\frac{d^{2} E_{r}\left(Q_{r}{ }^{*}, p\right)}{d p^{2}}=-2 k+\frac{\left(1-F\left(Q_{r}{ }^{*}\right)\right)^{2}}{(p-v+u) f\left(Q_{r}{ }^{*}\right)} .
$$

Similar to Proposition 3, we know that $E_{r}\left(Q_{r}{ }^{*}, p\right)$ is unimodal in $p$. If $w-u>c, d E_{r}\left(Q_{r}{ }^{*}, p\right) /\left.d p\right|_{p=w-u}=(a-$ $k(w-u))+\int_{0}^{\mathrm{Q}_{r}{ }^{*}(w-u)} \bar{F}(\xi) d \xi>0$. Thus, there exists a unique $p_{r}{ }^{*}$ which satisfies (19).

Remark 6. By Comparing (19) with (7) and (18) with (6), we find that $\left(Q_{\mathrm{sc}}{ }^{*}, p_{\mathrm{sc}}{ }^{*}\right)$ is the risk-neutral fashion retailer's optimal joint decision if and only if $u=0$ and $w=c$. However, a SRP contract with $u=0$ and $w=c$ gives the manufacturer zero profit. So SRP contract cannot coordinate the supply chain with risk-neutral fashion retailer and pricedependent demand.

4.2. Revenue-Sharing Contract. A revenue-sharing contract $\theta_{\mathrm{RS}}(w, \lambda)$ stipulates that the fashion retailer pays the upstream manufacturer a unit wholesale price $w$ for each unit ordered plus a proportion of his revenue from selling the product. Let $\lambda \in(0,1)$ be the fraction of supply chain revenue earned by the retailer, and thus $(1-\lambda)$ is the fraction shared by the manufacturer. Under the revenue-sharing contract $\theta_{\mathrm{RS}}(w, \lambda)$, the retailer's expected profit and the variance of profit are given as follows:

$$
\begin{gathered}
E_{r}(Q, p)=(\lambda p-w) D(p)+(\lambda p-w) Q \\
-\lambda(p-v) \int_{0}^{Q} F(\xi) d \xi, \\
V_{r}(Q, p)=\lambda^{2}(p-v)^{2} \eta(Q) .
\end{gathered}
$$

Proposition 7. For a given revenue-sharing contract $\theta_{R S}(w, \lambda)$ offered by the manufacturer, the risk-neutral fashion retailer's optimal joint decision $\left(\mathrm{Q}_{r}{ }^{*}, p_{r}{ }^{*}\right)$ is given by

$$
\begin{gathered}
\left(\lambda p_{r}{ }^{*}-w\right)-\lambda\left(p_{r}{ }^{*}-v\right) F\left(Q_{r}{ }^{*}\right)=0, \\
\lambda a-k\left(2 \lambda p_{r}{ }^{*}-w\right)+\lambda Q_{r}{ }^{*}-\lambda \int_{0}^{Q_{r}{ }^{*}} F(\xi) d \xi=0 .
\end{gathered}
$$

Proof. Similar to Proposition 5.

Remark 8. Comparing (28) with (6) and (29) with (7), we find that $\left(Q_{\mathrm{sc}}{ }^{*}, p_{\mathrm{sc}}{ }^{*}\right)$ can be the risk-neutral retailer's optimal 
ordering quantity and retail price if and only if $w=\lambda c<c$, which is equal to the optimal conditions for the contract parameters to coordinate the supply chain when retail price is given exogenously. Therefore, consistent with the finding in the literature [12], when the random demand is sensitive to pricing, revenue sharing contact with reasonable contract parameters is sufficient to coordinate the supply chain with risk-neutral retailer.

4.3. Two-Part Tariff Contract. With a two-part tariff contract $\theta_{\mathrm{TPT}}(w, G)$, the fashion retailer gives the manufacturer a fixed transfer payment $G>0$ apart from the unit wholesale price for each unit ordered. And the retailer's expected profit and the variance of profit are

$$
\begin{gathered}
E_{r}(Q, p)=(p-w) D(p)+(p-w) Q \\
-(p-v) \int_{0}^{Q} F(\xi) d \xi-G \\
V_{r}(Q, p)=E\left(\prod_{r}(Q, p)-E_{r}(Q, p)\right)^{2}=(p-v)^{2} \eta(Q) .
\end{gathered}
$$

Proposition 9. For a given two-part tariff contract $\theta_{T P T}(w, G)$ offered by the manufacturer, the risk-neutral fashion retailer's optimal joint decision $\left(Q_{r}{ }^{*}, p_{r}{ }^{*}\right)$ is given by

$$
\begin{gathered}
\left(p_{r}{ }^{*}-w\right)-\left(p_{r}{ }^{*}-v\right) F\left(Q_{r}{ }^{*}\right)=0 \\
a-k\left(2 p_{r}{ }^{*}-w\right)+Q_{r}{ }^{*}-\int_{0}^{Q_{r}{ }^{*}} F(\xi) d \xi=0 .
\end{gathered}
$$

Proof. Similar to Proposition 5.

Remark 10. By comparing (32) with (6) and (33) with (7), it is easy to get $w=c$, such that the independent retailer's optimal decisions $\left(Q_{r}{ }^{*}, p_{r}{ }^{*}\right)$ are equal to the integrated fashion supply chain's optimal solution $\left(Q_{\mathrm{sc}}{ }^{*}, p_{\mathrm{sc}}{ }^{*}\right)$. Hence, a two-part tariff contract $\theta_{\mathrm{TPT}}(w, G)$ could perfectly achieve channel coordination for a fashion supply chain with riskneutral retailer and price-dependent demand.

Now, by considering the risk aversion decision model, as given in (P-1), we establish the following propositions to attain the optimal joint decision for the risk-averse retailer under single contracts.

Proposition 11. Under single contracts, for any given $p \in$ $[w, a / k], V_{r}(Q, p)$ is strictly increasing in $Q$. For any given $Q \geq 0, V_{r}(Q, p)$ is strictly increasing in $p$.

Proof. From (17), (27), and (31), taking differentials of $V_{r}(Q, p)$ with respect to $Q$ and $p$, and since $d \eta(Q) / d Q=$ $2(1-F(Q)) \int_{0}^{Q} F(\xi) d \xi>0$, it can be easily verified that, for any given $p \in[w, a / k], V_{r}(Q, p)$ is strictly increasing in $Q$ and, for any given $Q \geq 0, V_{r}(Q, p)$ is strictly increasing in $p$.
Proposition 12. Given the retailer's expected threshold $k_{r} \leq$ $\bar{E}_{r}$, the risk-averse fashion retailer's optimal joint decision $\left(Q_{r, m v}{ }^{*}, p_{r, m v}{ }^{*}\right)$ satisfies

$$
\begin{gathered}
E_{r}\left(Q_{r, m v}{ }^{*}, p_{r, m v}{ }^{*}\right)=k_{r}, \\
Q_{r, m v}{ }^{*} \leq Q_{r}{ }^{*}, \\
p_{r, m v}{ }^{*} \leq p_{r}{ }^{*} .
\end{gathered}
$$

Proof. From the proceeding analysis, we know that under single contracts, such as SRP contract, revenue-sharing contract and two-part tariff contract, $E_{r}(Q, p)$ is a concave function of $Q$ and is unimodal in $p \in[w, a / k]$. Besides, $V_{r}(Q, p)$ is strictly increasing in $Q$ and $p$. Therefore, according to (P-1), the optimal pricing-inventory decision for the risk-averse fashion retailer is obtained by solving $E_{r}\left(Q_{r, m v}{ }^{*}, p_{r, m v}{ }^{*}\right)=k_{r}$. Moreover, since $k_{r} \leq \bar{E}_{r}$, in each region of $\left(Q \leq Q_{r}{ }^{*}, p \leq\right.$ $\left.p_{r}{ }^{*}\right),\left(Q>Q_{r}{ }^{*}, p \leq p_{r}{ }^{*}\right),\left(Q \leq Q_{r}{ }^{*}, p>p_{r}{ }^{*}\right)$, and $\left(Q>Q_{r}{ }^{*}, p>p_{r}{ }^{*}\right)$, there exists a corresponding decision pair $(Q, p)$ that could make $E_{r}(Q, p)=k_{r}$ established. Since $V_{r}(Q, p)$ is strictly increasing in $Q$ and $p$, the optimal solution $\left(Q_{r, m v}{ }^{*}, p_{r, m v}{ }^{*}\right)$ for $(\mathrm{P}-1)$ can only fall in the region $(Q \leq$ $\left.Q_{r}{ }^{*}, p \leq p_{r}{ }^{*}\right)$, otherwise, $\left(Q_{r, m v}{ }^{*}, p_{r, m v}{ }^{*}\right)$ cannot be the riskaverse fashion retailer's optimal joint decision. So we have $Q_{r, m v}{ }^{*} \leq Q_{r}{ }^{*}$ and $p_{r, m v}{ }^{*} \leq p_{r}{ }^{*}$.

Remark 13. From Proposition 12, we can know that the maximum expected profit of the risk-averse fashion retailer generated under single contracts is always no greater than that of a risk-neutral retailer. This is the loss of profit brought out by the retailer's risk aversion attitude or preference. In addition, it can be seen from Proposition 12 that under the additive price-dependent demand, the risk-averse fashion retailer tends to order less and charge a lower price in comparison with a risk-neutral retailer, which is consistent with the known results derived from the studies on joint pricing and inventory decisions of a risk-averse newsvendor $[29,33]$.

A contract provided by the upstream manufacturer is said to coordinate the supply chain if it is able to align the incentives of the manufacturer and the retailer so that the independent retailer makes the same decisions as the integrated supply chain, namely, $\left(Q_{r, m v}{ }^{*}, p_{r, m v}{ }^{*}\right)=\left(Q_{s c}{ }^{*}, p_{\mathrm{sc}}{ }^{*}\right)$. Now we present the following proposition to explore the necessary conditions for a contract to achieve channel coordination.

Proposition 14. For any given $k_{r}<\bar{E}_{s c}$, a contract achieves supply chain coordination if and only if the contract satisfies (1) $E_{r}\left(Q_{s c}{ }^{*}, p_{s c}{ }^{*}\right)=k_{r}$; (2) $\partial E_{r}\left(\mathrm{Q}, p_{s c}{ }^{*}\right) /\left.\partial Q\right|_{\mathrm{Q}=\mathrm{Q}_{s c}}{ }^{*} \geq 0$; (3) $\partial E_{r}\left(Q_{s c}{ }^{*}, p\right) /\left.\partial p\right|_{p=p_{s c}{ }^{*}} \geq 0$.

Proof. If a contract achieves supply chain coordination, then $\left(Q_{r, m v}{ }^{*}, p_{r, m v}{ }^{*}\right)=\left(Q_{s c}{ }^{*}, p_{\mathrm{sc}}{ }^{*}\right)$ stands. According to Proposition 12, we have $E_{r}\left(Q_{\mathrm{sc}}{ }^{*}, p_{\mathrm{sc}}{ }^{*}\right)=k_{r}$. On the other hand, since a contract coordinates the supply chain, from (P-1), we know that $E_{r}\left(Q_{\mathrm{sc}}{ }^{*}, p_{\mathrm{sc}}{ }^{*}\right) \geq k_{r}$. We know that $V_{r}(Q, p)$ is strictly increa-sing in $Q$ and $p$, and $E_{r}(Q, p)$ is a continuous function of $Q$ and $p$. If $E_{r}\left(Q_{s c}{ }^{*}, p_{s c}{ }^{*}\right)>k_{r}$ establishes, then there always exists an optimal joint decision $Q<Q_{s c}{ }^{*}$ and 
$p<p_{\mathrm{sc}}{ }^{*}$ such that $E_{r}(Q, p) \geq k_{r}$ and $V_{r}(Q, p)<V_{r}\left(Q_{\mathrm{sc}}{ }^{*}, p_{\mathrm{sc}}{ }^{*}\right)$, which contradicts the fact that $\left(Q_{\mathrm{sc}}{ }^{*}, p_{\mathrm{sc}}{ }^{*}\right)$ is the optimal joint pricing and inventory decisions for the risk-averse fashion retailer. Therefore, we have $E_{r}\left(Q_{\mathrm{sc}}{ }^{*}, p_{\mathrm{sc}}{ }^{*}\right)=k_{r}$.

If $\left(Q_{r, m v}{ }^{*}, p_{r, m v}{ }^{*}\right)=\left(Q_{s c}{ }^{*}, p_{s c}{ }^{*}\right)$, then according to Proposition $12, Q_{\mathrm{sc}}{ }^{*} \leq Q_{r}{ }^{*}$ and $p_{\mathrm{sc}}{ }^{*} \leq p_{r}{ }^{*}$. Since $E_{r}(Q, p)$ is a concave function of $Q$ and strictly increasing in $Q \in\left(0, Q_{r}{ }^{*}\right]$, from $Q_{\mathrm{sc}}{ }^{*} \leq \mathrm{Q}_{r}{ }^{*}$, we have $\partial E_{r}\left(\mathrm{Q}, p_{\mathrm{sc}}{ }^{*}\right) /\left.\partial \mathrm{Q}\right|_{\mathrm{Q}=\mathrm{Q}_{\mathrm{sc}}{ }^{*}} \geq 0$. Otherwise, if $\partial E_{r}\left(\mathrm{Q}, p_{\mathrm{sc}}{ }^{*}\right) /\left.\partial \mathrm{Q}\right|_{\mathrm{Q}=\mathrm{Q}_{\mathrm{sc}}{ }^{*}}<0$, and, because for any given $p \in[w, a / k], V_{r}(Q, p)$ is strictly increasing in $Q$, then there exists $Q<Q_{\mathrm{sc}}{ }^{*}$ such that $E_{r}\left(Q_{\mathrm{sc}}{ }^{*}, p_{\mathrm{sc}}{ }^{*}\right)<$ $E_{r}\left(Q, p_{s c}{ }^{*}\right)$ and $V_{r}\left(Q, p_{s c}{ }^{*}\right)<V_{r}\left(Q_{s c}{ }^{*}, p_{s c}{ }^{*}\right)$. It contradicts the fact that $\left(Q_{\mathrm{sc}}{ }^{*}, p_{\mathrm{sc}}{ }^{*}\right)$ is the optimal joint decision of the risk-averse fashion retailer. Similarly, $E_{r}(Q, p)$ is unimodal in $p \in[w, a / k]$; then, from $p_{\mathrm{sc}}{ }^{*} \leq$ $p_{r}{ }^{*}$, we have $\partial E_{r}\left(Q_{s c}{ }^{*}, p\right) /\left.\partial p\right|_{p=p_{s c}{ }^{*}} \geq 0$. Otherwise, if $\partial E_{r}\left(Q_{\mathrm{sc}}{ }^{*}, p\right) /\left.\partial p\right|_{p=p_{\mathrm{sc}}{ }^{*}}<0$ and because $V_{r}(Q, p)$ is strictly increasing in $p$ for any given $Q \geq 0$, then there exists $p<p_{\mathrm{sc}}{ }^{*}$ such that $E_{r}\left(Q_{\mathrm{sc}}{ }^{*}, p_{\mathrm{sc}}{ }^{*}\right)<E_{r}\left(Q_{\mathrm{sc}}{ }^{*}, p\right)$ and $V_{r}\left(Q_{\mathrm{sc}}{ }^{*}, p\right)<V_{r}\left(Q_{\mathrm{sc}}{ }^{*}, p_{\mathrm{sc}}{ }^{*}\right)$. It contradicts the fact that $\left(Q_{s c}{ }^{*}, p_{s c}{ }^{*}\right)$ is the optimal joint decision of the risk-averse fashion retailer. As a result, we have $\partial E_{r}\left(Q, p_{s c}{ }^{*}\right) /\left.\partial Q\right|_{Q=Q_{s c}}{ }^{*} \geq$ 0 and $\partial E_{r}\left(Q_{s c}{ }^{*}, p\right) /\left.\partial p\right|_{p=p_{s c}{ }^{*}} \geq 0$.

Remark 15. From Proposition 14, it can be derived that when the supply chain is coordinated, the risk-averse fashion retailer's expected profit is equal to $k_{r}$, and hence the manufacturer's expected profit is equal to $\bar{E}_{\mathrm{sc}}-k_{r}$.

Next, we investigate in more detail whether the single contracts above could achieve supply chain coordination.

Proposition 16. For any given $k_{r}<\bar{E}_{s c}$, SRP contract cannot achieve supply chain coordination.

Proof. From Proposition 14, we can get that the supply chain achieves coordination if and only if SRP contract satisfies $E_{r}\left(Q_{\mathrm{sc}}{ }^{*}, p_{\mathrm{sc}}{ }^{*}\right)=k_{r}, \partial E_{r}\left(\mathrm{Q}, p_{\mathrm{sc}}{ }^{*}\right) /\left.\partial \mathrm{Q}\right|_{\mathrm{Q}=\mathrm{Q}_{\mathrm{sc}}{ }^{*}} \geq 0$, and $\partial E_{r}\left(Q_{\mathrm{sc}}{ }^{*}, p\right) /\left.\partial p\right|_{p=p_{\mathrm{sc}}} \geq 0$.

From $\partial E_{r}\left(Q, p_{s c}{ }^{*}\right) /\left.\partial Q\right|_{Q=Q_{s c}}{ }^{*} \geq 0$, we can get $\left(p_{s c}{ }^{*}-w\right)-$ $\left(p_{\mathrm{sc}}{ }^{*}-v\right) F\left(\mathrm{Q}_{\mathrm{sc}}{ }^{*}\right)+u \bar{F}\left(Q_{\mathrm{sc}}{ }^{*}\right) \geq 0$. And from (6), we have $u \bar{F}\left(Q_{s c}{ }^{*}\right) \geq w-c$. From $\partial E_{r}\left(Q_{s c}{ }^{*}, p\right) /\left.\partial p\right|_{p=p_{s c}{ }^{*}} \geq 0$, we have $a-k\left(2 p_{\mathrm{sc}}{ }^{*}-w+u\right)+Q_{\mathrm{sc}}{ }^{*}-\int_{0}^{\mathrm{Q}{ }^{*}} F(\xi) d \xi \geq 0$. And from (7), it can be obtained that $u \leq w-c$. Since $u \bar{F}\left(Q_{s c}{ }^{*}\right)<u$, there does not exist some value of $u$ such that $u \bar{F}\left(Q_{\mathrm{sc}}{ }^{*}\right) \geq w-c$ and $u \leq$ $w-c$ establish simultaneously. In other words, SRP contract $\theta_{\mathrm{SRP}}(w, t, u)$ cannot achieve channel coordination.

Proposition 17. For any given $k_{r}<\bar{E}_{s c}$, revenue-sharing contract and two-part tariff contract can achieve channel coordination. Specifically, the optimal conditions satisfied by the contract parameters of these two contracts to coordinate the supply chain are as follows:

(1) for revenue-sharing contract, $w=\lambda c, \lambda=k_{r} / \bar{E}_{s c}$;

(2) for two-part tariff contract, $w=c, G=\bar{E}_{s c}-k_{r}$.
Proof. According to Proposition 14, for the revenue-sharing contract, from $E_{r}\left(Q_{\mathrm{sc}}{ }^{*}, p_{\mathrm{sc}}{ }^{*}\right)=k_{r}$, we get the expression $w=\lambda p_{\mathrm{sc}}{ }^{*}-\left(k_{r}+\lambda\left(p_{\mathrm{sc}}{ }^{*}-v\right) \int_{0}^{\mathrm{Q}_{\mathrm{sc}}{ }^{*}} F(\xi) d \xi\right) / q_{\mathrm{sc}}{ }^{*}$. From $\partial E_{r}\left(\mathrm{Q}, p_{\mathrm{sc}}{ }^{*}\right) /\left.\partial \mathrm{Q}\right|_{\mathrm{Q}=Q_{\mathrm{sc}}{ }^{*}} \geq 0$, we have $\lambda p_{\mathrm{sc}}{ }^{*}-w-\lambda\left(p_{\mathrm{sc}}{ }^{*}-\right.$ v) $F\left(Q_{\mathrm{sc}}{ }^{*}\right) \geq 0$. Substituting (6) into $\lambda p_{\mathrm{sc}}{ }^{*}-w-\lambda\left(p_{\mathrm{sc}}{ }^{*}-\right.$ v) $F\left(Q_{\mathrm{sc}}{ }^{*}\right) \geq 0$, it can be calculated that $w \leq \lambda c$. From $\partial E_{r}\left(Q_{s c}{ }^{*}, p\right) /\left.\partial p\right|_{p=p_{s c}{ }^{*}} \geq 0$, we get $\lambda a-k\left(2 \lambda p_{s c}{ }^{*}-w\right)+$ $\lambda Q_{\mathrm{sc}}{ }^{*}-\lambda \int_{0}^{\mathrm{Q}_{\mathrm{sc}}{ }^{*}} F(\xi) d \xi \geq 0$, and, taking (7) into it, we know that $w \geq \lambda c$. Combining $w \leq \lambda c$ and $w \geq \lambda c$, we have $w=\lambda c$, and, by taking $w=\lambda c$ into the expression of $w$, we have $\lambda=k_{r} / \bar{E}_{s c}$. Hence, revenue-sharing contract can still coordinate the supply chain, when the fashion retailer is risk averse.

Similarly, for two-part tariff contract, from $E_{r}\left(Q_{s c}{ }^{*}\right.$, $\left.p_{\mathrm{sc}}{ }^{*}\right)=k_{r}$, we have $w=p_{\mathrm{sc}}{ }^{*}-\left(k_{r}+\left(p_{\mathrm{sc}}{ }^{*}-v\right) \int_{0}^{\mathrm{Q}{ }^{*}} F(\xi) d \xi+\right.$ $G) / q_{\mathrm{sc}}{ }^{*}$. From $\partial E_{r}\left(Q, p_{\mathrm{sc}}{ }^{*}\right) /\left.\partial Q\right|_{\mathrm{Q}-\mathrm{Q}_{\mathrm{sc}}{ }} \geq 0$, we get $p_{\mathrm{sc}}{ }^{*}-w-$ $\left(p_{\mathrm{sc}}{ }^{*}-v\right) F\left(Q_{\mathrm{sc}}{ }^{*}\right) \geq 0$, and, from $(6), w \leq c$ is derived. From $\partial E_{r}\left(Q_{\mathrm{sc}}{ }^{*}, p\right) /\left.\partial p\right|_{p=p_{\mathrm{sc}}{ }^{*}} \geq 0$, we get $a-k\left(2 p_{\mathrm{sc}}{ }^{*}-w\right)+Q_{\mathrm{sc}}{ }^{*}-$ $\int_{0}^{\mathrm{Q}_{\mathrm{sc}}{ }^{*}} F(\xi) d \xi \geq 0$, and, from (7), we have $w \geq c$. Thus, we have $w=c$. Comparing $w=c$ and $w=p_{\mathrm{sc}}{ }^{*}-\left[\left(k_{r}+\left(p_{\mathrm{sc}}{ }^{*}-\right.\right.\right.$ v) $\left.\left.\int_{0}^{\mathrm{Q}_{\mathrm{sc}}{ }^{*}} F(\xi) d \xi+G\right) / q_{\mathrm{sc}}{ }^{*}\right]$, we can get $G=\bar{E}_{\mathrm{sc}}-k_{r}$. Therefore, two-part tariff also could achieve supply chain coordination with risk sensitive retailer.

Remark 18. From Propositions 16 and 17, we find that when the end demand depends on retail price and the fashion retailer is risk sensitive, a more complex SRP contract (with three parameters) cannot achieve supply chain coordination, whereas simpler revenue-sharing contract and two-part tariff contract (with two parameters) can.

From Proposition 17, the values of $\lambda$ and $G$ can be regarded as indicators of the fashion retailer's risk aversion level. Specifically, with a larger $\lambda$, the expected profit threshold of the retailer $k_{r}$ is greater, and the retailer is more risk averse. Contrarily, a larger value of $G$ means a smaller expected profit threshold for the retailer, indicating a less risk sensitive retailer. As a result, if the fraction of sales revenue or the value of fixed transfer payment which the fashion retailer is willing to offer to the manufacturer is small, then the retailer is relatively more risk averse.

\section{The Decentralized Fashion Supply Chain under Combined Contracts}

In the above section, we investigate the role of three single contracts in coordinating fashion supply chains and find that a more complicated SRP contract fails to coordinate the supply chain while two other simpler contracts perfectly achieve channel coordination. In this section, we further explore contracts that combine the advantages of the above contracts. Specifically, we try to explore whether the resulting contracts are effective to coordinate the supply chain when the coordinating contracts and the failed contract combine with each other. Define similarly $Q=q-D(p), T=t-D(p)$, and $T^{*}=t-D\left(p^{*}\right)$. 
5.1. SRP with Revenue-Sharing Contract. Under this contract, the fashion retailer's profit, expected profit, and the variance of profit are

$$
\begin{aligned}
& \prod_{r}(Q, p) \\
&=(\lambda p-w) D(p)+(\lambda p-w) Q-\lambda(p-v)(Q-\xi)^{+} \\
&+u(\min (\xi, Q)-T),
\end{aligned}
$$

$E_{r}(Q, p)$

$$
\begin{gathered}
=(\lambda p-w) D(p)+(\lambda p-w) Q \\
-\lambda(p-v) \int_{0}^{Q} F(\xi) d \xi+u\left(Q-T-\int_{0}^{Q} F(\xi) d \xi\right), \\
V_{r}(Q, p)=[\lambda(p-v)+u]^{2} \eta(Q) .
\end{gathered}
$$

Proposition 19. For a given SRP with revenue-sharing contract offered by the manufacturer, the risk-neutral fashion retailer's optimal joint decision $\left(Q_{r}{ }^{*}, p_{r}{ }^{*}\right)$ is given by

$$
\begin{gathered}
\left(\lambda p_{r}{ }^{*}-w+u\right)-\left[\lambda\left(p_{r}{ }^{*}-v\right)+u\right] F\left(Q_{r}{ }^{*}\right)=0, \\
\lambda a-k\left(2 \lambda p_{r}{ }^{*}-w+u\right)+\lambda Q_{r}{ }^{*}-\lambda \int_{0}^{Q_{r}{ }^{*}} F(\xi) d \xi=0 .
\end{gathered}
$$

Proof. Similar to Proposition 5.

Remark 20. By comparing (39) with (7) and (38) with (6), we find that when $u=0, w=\lambda c,\left(Q_{r}{ }^{*}, p_{r}{ }^{*}\right)=\left(Q_{\mathrm{sc}}{ }^{*}, p_{\mathrm{sc}}{ }^{*}\right)$ establishes. However, it contradicts the assumption of $u>0$ in SRP with revenue-sharing contract. Thus, when the fashion retailer is risk-neutral, SRP with revenue-sharing contract cannot achieve channel coordination.

5.2. SRP with Two-Part Tariff Contract. In this setting, the fashion retailer's expected profit and the variance of profit are given by

$$
\begin{aligned}
& E_{r}(Q, p) \\
& \qquad \begin{array}{l}
(p-w) D(p)+(p-w) Q-(p-v) \int_{0}^{Q} F(\xi) d \xi \\
+u\left(Q-T-\int_{0}^{Q} F(\xi) d \xi\right)-G \\
V_{r}(Q, p)=(p-v+u)^{2} \eta(Q) .
\end{array}
\end{aligned}
$$

Proposition 21. For a given SRP with two-part tariff contract offered by the manufacturer, the risk-neutral fashion retailer's optimal joint decision $\left(Q_{r}{ }^{*}, p_{r}{ }^{*}\right)$ is given by

$$
\begin{array}{r}
\left(p_{r}{ }^{*}-w+u\right)-\left(p_{r}^{*}-v+u\right) F\left(Q_{r}^{*}\right)=0, \\
a-k\left(2 p_{r}^{*}-w+u\right)+Q_{r}^{*}-\int_{0}^{Q_{r}^{*}} F(\xi) d \xi=0 .
\end{array}
$$

Remark 22. Comparing (41) with (18) and (42) with (19), we discover that, under SRP with two-part tariff contract, the risk-neutral fashion retailer's optimal decisions are equal to those under a single SRP contract. Therefore, consistent with the analysis in Section 4, SRP with two-part tariff contract cannot coordinate the supply chain with risk-averse retailer and price-dependent demand.

5.3. Revenue Sharing with Two-Part Tariff Contract. Under a revenue sharing with two-part tariff contract, the fashion retailer's expected profit and the variance of profit are as follows:

$$
\begin{gathered}
E_{r}(Q, p)=(\lambda p-w) D(p)+(\lambda p-w) Q \\
-\lambda(p-v) \int_{0}^{Q} F(\xi) d \xi-G, \\
V_{r}(Q, p)=\lambda^{2}(p-v)^{2} \eta(Q) .
\end{gathered}
$$

Similar to SRP with two-part tariff contract, the optimal joint ordering-pricing decision for the risk-neutral fashion retailer under revenue sharing with two-part tariff contract is equal to that under a single revenue-sharing contract. Hence, revenue sharing with two-part tariff contract is able to achieve channel coordination in the fashion supply chain with riskaverse retailer and price-dependent demand.

As a result, it only remains uncertain whether SRP with revenue-sharing contract could achieve supply chain coordination with risk-averse retailer. Following the similar approach as presented in Section 4, we now investigate the role of SRP with revenue-sharing contract in channel coordination.

From (37), by some simple deductions, we know that, under SRP with revenue-sharing contract, $V_{r}(Q, p)$ is strictly increasing in $Q$ and $p$. Therefore, with any given expected threshold $k_{r} \leq \bar{E}_{r}$, the risk-averse retailer's optimal joint decision $\left(Q_{r, m v}{ }^{*}, p_{r, m v}{ }^{*}\right)$ satisfies (34).

Proposition 23. For any given $k_{r}<\bar{E}_{s c}$, SRP with revenuesharing contract cannot achieve supply chain coordination.

Proof. From Proposition 14, we know that channel coordination is obtained if and only if SRP with revenuesharing contract satisfies $E_{r}\left(Q_{\mathrm{sc}}{ }^{*}, p_{\mathrm{sc}}{ }^{*}\right)=k_{r}, \partial E_{r}(Q$, $\left.p_{\mathrm{sc}}{ }^{*}\right) /\left.\partial Q\right|_{\mathrm{Q}=Q_{\mathrm{sc}}{ }^{*}} \geq 0$, and $\partial E_{r}\left(Q_{\mathrm{sc}}{ }^{*}, p\right) /\left.\partial p\right|_{p=p_{\mathrm{sc}}{ }^{*}} \geq 0$. From $\partial E_{r}\left(Q, p_{\mathrm{sc}}{ }^{*}\right) /\left.\partial Q\right|_{\mathrm{Q}=\mathrm{Q}_{\mathrm{sc}}{ }^{*}} \geq 0$, we have $\left(\lambda p_{\mathrm{sc}}{ }^{*}-w\right)-$ $\lambda\left(p_{\mathrm{sc}}{ }^{*}-v\right) F\left(Q_{\mathrm{sc}}{ }^{*}\right)+u \bar{F}\left(Q_{\mathrm{sc}}{ }^{*}\right) \geq 0$. Combining with (6), we can derive that $u \bar{F}\left(Q_{s c}{ }^{*}\right) \geq w-\lambda c$. Nonetheless, from $\partial E_{r}\left(Q_{s c}{ }^{*}, p\right) /\left.\partial p\right|_{p=p_{s c}{ }^{*}} \geq 0$, we get $\lambda a-k\left(2 \lambda p_{\mathrm{sc}}{ }^{*}-w+\right.$ $u)+\lambda\left(Q_{\mathrm{sc}}{ }^{*}-\int_{0}^{\mathrm{Q}_{\mathrm{sc}}{ }^{*}} F(\xi) d \xi\right) \geq 0$, and, from (7), by some simplifications, we have $u \leq w-\lambda c$. Since $u \bar{F}\left(Q_{\mathrm{sc}}{ }^{*}\right)<$ $u$, there does not exist some value of $u$ that could satisfy $u \bar{F}\left(Q_{\mathrm{sc}}{ }^{*}\right) \geq w-\lambda c$ and $u \leq w-\lambda c$ simultaneously. Thus, SRP with revenue-sharing contract cannot coordinate the fashion supply chain. 
TABLE 1: Optimal values of contract parameters for different values of $k_{r}$.

\begin{tabular}{|c|c|c|c|c|c|c|c|}
\hline \multirow{2}{*}{$k_{r}$} & \multicolumn{2}{|c|}{ Revenue-sharing contract } & \multicolumn{2}{|c|}{ Two-part tariff contract } & \multicolumn{3}{|c|}{ Revenue sharing with two-part tariff contract } \\
\hline & $w$ & $\lambda$ & $w$ & G & $\lambda$ & $w$ & G \\
\hline 1000 & 2.37 & 0.16 & 15 & 5326.70 & 0.2 & 3 & 265.34 \\
\hline 2000 & 4.74 & 0.32 & 15 & 4326.70 & 0.4 & 6 & 530.68 \\
\hline 3000 & 7.11 & 0.47 & 15 & 3326.70 & 0.5 & 7.5 & 163.35 \\
\hline 4000 & 9.48 & 0.63 & 15 & 2326.70 & 0.7 & 10.5 & 428.69 \\
\hline 5000 & 11.85 & 0.79 & 15 & 1326.70 & 0.8 & 12 & 61.36 \\
\hline 6000 & 14.23 & 0.95 & 15 & 326.70 & 0.96 & 14.4 & 73.63 \\
\hline
\end{tabular}

Remark 24. It is interesting to discover that, although a single revenue-sharing contract itself could coordinate the quantity and pricing decisions in the fashion supply chain with risk sensitive retailer, the combined SRP with revenue-sharing contract cannot optimize the whole supply chain's profit. To some extent, this means that, when faced with more intricate supply chain circumstance, perhaps a simpler contract is more effective and efficient to achieve channel coordination in comparison with a more complicated one.

Furthermore, when a single revenue-sharing contract and a single two-part tariff contract can coordinate the supply chain with risk-averse retailer and price-dependent demand, a composite contract of these two contracts would still be effective to coordinate the supply chain. Instead, a single SRP contract cannot achieve channel coordination; thus when it combines with revenue-sharing contract or two-part tariff contract, the resulting combined contract is still unable to coordinate the fashion supply chain.

\section{Numerical Analysis}

In this section, we present numerical analysis to gain more insights on supply chain coordination with contracts. We focus on the coordinating revenue-sharing contract, twopart tariff contract, and the combined revenue sharing with two-part tariff contract here. Numerical analysis can be decomposed into two parts: one is to investigate how to determine the optimal values of contract parameters, and the other is sensitivity analysis to explore the impacts of some important parameters on supply chain coordination and objectives of supply chain members.

6.1. Determine the Values of Contract Parameters. First, we give the values of parameters used in this section. Suppose the base demand $a=600$ and the price elasticity of demand $k=$ 10 . The random variable $\xi$ follows a uniform distribution with a lower bound $A=0$ and an upper bound $B=160$. The unit production $\operatorname{cost} c=15$, and the unit salvage value $v=2$. With these parameters, the optimal joint decision that maximizes the expected profit of the integrated fashion supply chain is $Q_{\mathrm{sc}}{ }^{*}=106.74$ and $p_{\mathrm{sc}}{ }^{*}=41.06$, and the supply chain's optimal production level is given by $q_{\mathrm{sc}}{ }^{*}=296.18$. The respective expected profit and the variance of profit for the fashion supply chain are $\bar{E}_{\mathrm{sc}}=6326.70$ and $V_{\mathrm{sc}}\left(\mathrm{Q}_{\mathrm{sc}}{ }^{*}, p_{\mathrm{sc}}{ }^{*}\right)=$
1931261.13. Since the expected profit threshold for the riskaverse retailer must be smaller than the maximum expected profit gained by the fashion supply chain, we assume $k_{r}<$ 6326.70 in the following analysis.

We consider six values of $k_{r}=1000,2000,3000,4000$, 5000 , and 6000 to explore the optimal values of contract parameters for the coordinating contracts above. It should be noted that for the combined revenue sharing with two-part tariff contract, $\lambda>k_{r} / \bar{E}_{\mathrm{sc}}$ must establish to ensure that $G>0$. The results are summarized in Table 1.

From Table 1, we can see the effectiveness of revenue sharing, two-part tariff, and their combined contract in coordinating the fashion supply chain. Consistent with Proposition 17, $\lambda$ in revenue-sharing contract and $G$ in twopart tariff contract can be used to judge the downstream fashion retailer's risk aversion level. For revenue-sharing contract, with a larger $k_{r}$, the retailer is more risk averse, thus leading to a higher fraction of sales revenue kept by the retailer himself. By anticipating the retailer's response, the manufacturer would react by setting a higher wholesale price $w$. For two-part tariff contract, a wholesale price $w$ equaling to the unit production $c$ gives the manufacturer zero profit, but the fixed transfer payment $G$ ensures a positive profit for the manufacturer. And a higher value of $G$ which the retailer is willing to pay indicates a less risk-averse retailer. In combined contract, for the retailer's same risk aversion degrees, the proposition of sales revenue kept by the retailer himself must be larger than that in the single revenue-sharing contract, owing to the fact that the fashion retailer must pay the manufacturer an additional fixed payment in the combined contract.

6.2. Sensitivity Analysis. Now, we study the effects of some important parameters on supply chain coordination and objectives of supply chain members. Firstly, we focus on revenue-sharing contract with parameters such as base demand $a$, price elasticity of demand $k$, and demand uncertainty. The results are given in Table 2.

From Table 2, we find that, with the increase of base demand $a$, the optimal production quantity $q_{\mathrm{sc}}{ }^{*}$ and pricing $p_{\mathrm{sc}}{ }^{*}$ for the integrated fashion supply chain also increase, leading to larger expected profit $\bar{E}_{\mathrm{sc}}$ and the variance of profit $V_{\mathrm{sc}}$. This is consistent with Proposition 3 that $E_{\mathrm{sc}}$ is a concave function of $q$ and is unimodal in $p$, and $V_{\mathrm{sc}}$ is strictly increasing in $q$ and $p$. Taking into account $k_{r}<\bar{E}_{\mathrm{sc}}$, we 
TABLE 2: Sensitivity analysis for revenue-sharing contract.

\begin{tabular}{ccccccccccc}
\hline \multicolumn{2}{c}{ Parameter } & $Q_{\mathrm{sc}}{ }^{*}$ & $q_{\mathrm{sc}}{ }^{*}$ & $p_{\mathrm{sc}}{ }^{*}$ & $k_{r}$ & $w$ & $\lambda$ & $\bar{E}_{\mathrm{sc}}$ & $V_{\mathrm{sc}}$ \\
\hline & 400 & 87.47 & 180.69 & 30.68 & 2000 & 13.97 & 0.93 & 2147.18 & 676524.01 & 586954.45 \\
& 500 & 98.67 & 239.54 & 35.91 & 3000 & 11.31 & 0.75 & 3977.72 & 1236932.08 & 703589.94 \\
& 600 & 106.74 & 296.18 & 41.06 & 5000 & 11.85 & 0.79 & 6362.70 & 1931261.13 & 1206220.67 \\
& 700 & 112.89 & 351.36 & 46.15 & 8000 & 13.06 & 0.87 & 9187.50 & 2751202.56 & 2085967.18 \\
& 800 & 117.74 & 405.53 & 51.22 & 10000 & 11.95 & 0.80 & 12556.40 & 3691564.92 & 2341424.45 \\
& 900 & 121.67 & 458.97 & 56.27 & 14000 & 12.78 & 0.85 & 16431.10 & 4748912.61 & 3447602.58 \\
& 1000 & 124.93 & 511.85 & 61.31 & 20000 & 14.42 & 0.96 & 20810.09 & 5920873.15 & 5468870.88 \\
\hline \multirow{4}{*}{$k$} & 10 & 106.74 & 296.18 & 41.06 & 200 & 0.47 & 0.03 & 6362.70 & 1931261.13 & 1929.95 \\
& 15 & 84.57 & 240.96 & 29.57 & 200 & 1.04 & 0.07 & 2895.46 & 578223.79 & 2758.79 \\
& 20 & 64.53 & 188.77 & 23.79 & 200 & 2.18 & 0.15 & 1375.39 & 185400.79 & 3920.33 \\
& 25 & 46.29 & 138.99 & 20.29 & 200 & 4.89 & 0.33 & 613.05 & 54132.63 & 5761.4 \\
& 30 & 29.57 & 91.15 & 17.95 & 200 & 13.33 & 0.89 & 225.07 & 11800.57 & 9317.77 \\
\hline & $15 \%$ & 118.25 & 290.64 & 42.76 & 4000 & 8.15 & 0.53 & 7537.51 & 269951.09 & 76023.73 \\
& $35 \%$ & 255.40 & 383.92 & 47.15 & 4000 & 6.30 & 0.42 & 9522.90 & 6935423.41 & 1223642.39 \\
& $55 \%$ & 296.77 & 424.47 & 47.23 & 4000 & 6.62 & 0.44 & 9059.38 & 18604230.72 & 3626893.02 \\
& $75 \%$ & 94.84 & 291.40 & 40.34 & 4000 & 10.12 & 0.67 & 5930.02 & 2154476.37 & 980278.33 \\
& $95 \%$ & 45.88 & 258.58 & 38.73 & 4000 & 11.21 & 0.75 & 5354.43 & 649949.19 & 362321.17 \\
\hline
\end{tabular}

consider the appropriate values of $k_{r}$ and find that the optimal values of $w$ and $V_{r}$ do not exhibit some rule of changes since $\lambda$ changes randomly. However, when we fix the value of $k_{r}$ in the region $k_{r}<\bar{E}_{\mathrm{sc}}$ for all cases of $a$, we could intuitively reach the conclusion that the values of $\lambda, w$, and $V_{r}$ tend to decrease.

However, it can be found from Table 2 that with larger values of price elasticity $k$, the entire supply chain's optimal production quantity and retail price become smaller, so do the supply chain's expected profit $\bar{E}_{\mathrm{sc}}$ and the variance of profit $V_{\mathrm{sc}}$. On the contrary, by fixing values of $k_{r}$ subject to $k_{r}<\bar{E}_{\mathrm{sc}}$, we discover that the values of $w, \lambda$, and $V_{r}$ all become larger.

In addition, we also try to illustrate the effect of different degrees of demand uncertainty. We define demand uncertainty as $\mathrm{CV}=\theta / \delta$, where $\delta$ represents the mean and $\theta$ denotes the standard variance of the random demand. We could derive from Table 2, that when the level of demand uncertainty increases, the optimal joint quantity and pricing decisions for the fashion supply chain incline to firstly increase and then decrease. Thus, the supply chain's expected profit $\bar{E}_{\mathrm{sc}}$ and the variance of profit $V_{\mathrm{sc}}$ also have the same rule of changes. With respect to the values of $w$ and $\lambda$, they change toward the opposite direction. The combined changes of $\lambda$ and $V_{\text {sc }}$ cause the changes of $V_{r}$.

Similarly, following the same method, we could also get the results of sensitivity analysis for the other two coordinating contracts - two-part tariff contract and revenue sharing with two-part tariff contract. They are summarized in Tables 3 and 4, respectively.

From Table 3, it can be easily discovered that no matter how the values of parameter $a, k$, and CV change, the optimal values of $w$ are always equal to 15 . But the optimal values of $G$ are dependent upon the change in values of those parameters.
TABLE 3: Sensitivity analysis for two-part tariff contract.

\begin{tabular}{cccccc}
\hline \multicolumn{2}{c}{ Parameter } & $k_{r}$ & $w$ & $G$ & $V_{r}$ \\
\hline & 400 & 2000 & 15 & 147.18 & 676524.01 \\
& 500 & 3000 & 15 & 977.72 & 1236932.08 \\
& 600 & 5000 & 15 & 1326.70 & 1931261.13 \\
& 700 & 8000 & 15 & 1187.50 & 2751202.56 \\
& 800 & 10000 & 15 & 2556.40 & 3691564.92 \\
& 900 & 14000 & 15 & 2431.11 & 4748912.61 \\
& 1000 & 20000 & 15 & 810.09 & 5920873.15 \\
\hline \multirow{4}{*}{$k$} & 10 & 200 & 15 & 6126.70 & 1931261.13 \\
& 15 & 200 & 15 & 2659.46 & 578223.79 \\
& 20 & 200 & 15 & 1175.39 & 185400.79 \\
& 25 & 200 & 15 & 413.05 & 54132.63 \\
& 30 & 200 & 15 & 25.07 & 11800.57 \\
\hline \multirow{4}{*}{ CV } & $15 \%$ & 4000 & 15 & 3537.51 & 269951.09 \\
& $35 \%$ & 4000 & 15 & 5522.90 & 6935423.41 \\
& $55 \%$ & 4000 & 15 & 5059.38 & 18604230.72 \\
& $75 \%$ & 4000 & 15 & 1930.02 & 2154476.37 \\
& $95 \%$ & 4000 & 15 & 1354.43 & 649949.19 \\
\hline
\end{tabular}

Specifically, the optimal $G$ equals $\bar{E}_{\mathrm{sc}}-k_{r}$. When parameters $k$ and CV change, the integrated fashion supply chain's optimal expected profit $\bar{E}_{\mathrm{sc}}$ also change as shown in Table 2. If the values of $k_{r}$ are fixed, $G$ changes positively with the changes of $\bar{E}_{\mathrm{sc}}$. That is, the values of $G$ decrease in the case of $k_{r}$ and firstly increase and then decrease in the case of CV.

Similar analysis could be realized for the joint revenue sharing with two-part tariff contract. What is worth noting here is that, in Table 4, we could find that the values of $\lambda$ are larger than the corresponding values in Table 2 for the single revenue-sharing contract, whereas the values of $G$ are 
TABLE 4: Sensitivity analysis for revenue-sharing with two-part tariff contract.

\begin{tabular}{ccccccc}
\hline \multicolumn{1}{c}{ Parameter } & $k_{r}$ & $\lambda$ & $w$ & $G$ & $V_{r}$ \\
\hline \multirow{4}{*}{$a$} & 400 & 2000 & 0.95 & 14.25 & 39.83 & 610562.93 \\
& 500 & 3000 & 0.8 & 12 & 182.18 & 791636.53 \\
& 600 & 5000 & 0.8 & 12 & 61.36 & 1236007.12 \\
& 700 & 8000 & 0.9 & 13.5 & 268.75 & 2228474.07 \\
& 800 & 10000 & 0.85 & 12.75 & 672.94 & 2667155.65 \\
& 900 & 14000 & 0.9 & 13.5 & 787.99 & 3846619.22 \\
& 1000 & 20000 & 0.98 & 14.7 & 393.89 & 5686406.57 \\
\hline \multirow{4}{*}{$k$} & 10 & 200 & 0.1 & 1.5 & 432.67 & 19312.61 \\
& 15 & 200 & 0.2 & 3 & 379.09 & 23128.95 \\
& 20 & 200 & 0.4 & 6 & 350.15 & 29664.13 \\
& 25 & 200 & 0.7 & 10.5 & 229.13 & 26524.99 \\
& 30 & 200 & 0.9 & 13.5 & 2.56 & 9558.46 \\
\hline \multirow{4}{*}{ CV } & $15 \%$ & 4000 & 0.7 & 10.5 & 1276.26 & 132276.03 \\
& $35 \%$ & 4000 & 0.6 & 9 & 1713.74 & 2496752.43 \\
& $55 \%$ & 4000 & 0.5 & 7.5 & 529.69 & 4651057.68 \\
& $75 \%$ & 4000 & 0.8 & 12 & 744.02 & 1378864.88 \\
& $95 \%$ & 4000 & 0.9 & 13.5 & 818.99 & 526458.84 \\
\hline
\end{tabular}

smaller than the corresponding values in the single two-part tariff contract. This is because, in the combined contract, the fashion retailer cannot keep all the sales revenue but has to pay an additional fixed transfer payment to the manufacturer. Accordingly, the values of the variance of profit $V_{r}$ in revenue sharing with two-part tariff contract are always larger than the respective values in revenue-sharing contract alone, while they obtain their largest values in two-part tariff contract since they are equal to the according values of $V_{\mathrm{sc}}$.

\section{Management Insights and Concluding Remark}

In this paper, the issue of supply chain coordination with risk-averse retailer and price-dependent demand is studied. We extend in this paper the previous works to consider a risk-averse retailer in a two-stage fashion supply chain. Adopting the additive price-sensitive demand model, we construct the benchmark solution to the integrated fashion supply chain. Using the classic MV formulation in portfolio management in finance to characterize the risk sensitive fashion retailer's decision models, we propose both single contracts and combined contracts to achieve channel coordination. We find that, under single contracts, the coordinating revenue-sharing contract and two-part tariff contract in supply chains with risk-neutral agents could still coordinate the supply chain with risk sensitive retailer. However, a more complicated sales rebate and penalty contract fails to do so. Then we try to combine traditional single contracts to explore whether the resulting joint contracts are useful to coordinate the supply chain. It is found that only the joint revenue sharing with two-part tariff contract is able to achieve supply chain coordination. By presenting numerical analysis to illustrate analytical results, we discuss the determination of optimal values of contract parameters in coordinating contracts as well as sensitivity analysis to explore the effects of base demand, price elasticity, and the degree of demand uncertainty on supply chain coordination and objectives of supply chain members.

We highlight the managerial insights of our results in the following. Mean-variance formulation for risk analysis in supply chains is intuitive to decisions makers, making it easy and applicable for managers and practitioners in fashion supply chains to use proposed models to determine the type of contract and the optimal values of contract parameters to achieve channel coordination. This paper captures the fundamental feature of retailing fashion channel that the fashion retailer could influence the end demand by setting appropriate retail price. Our findings indicate that, in such complicated retailing situation, it may be more effective for real managers to adopt relatively simple contracts, so as to achieve coordination. Moreover, the theoretical results offer references to decision makers on the conditions a contract must satisfy to coordinate fashion supply chains, which is significant for improving efficiency in such supply chains with effective retailing channels and fashion retailer's risk aversion preference or attitude.

In this paper, we just focus on channel coordination in single period, single manufacture, and single retailer fashion supply chain. Future research on supply chain coordination over multiple periods or with multiple competing risk-averse retailers would be a meaningful direction and could produce more insights.

\section{Acknowledgments}

The authors sincerely thank the Editor-in-Chief and the three anonymous reviewers for their valuable comments and suggestions on the revision of the paper. This paper was supported in part by (1) the Fund for Humanity and Social Science of the Ministry of Education, China, under Grant 09YJC630230; (2) the Natural Science Foundation of Hunan Province, China, under Grant 10JJ3023.

\section{References}

[1] T. M. Choi, Fashion Supply Chain Management: Industry and Business Analysis, IGI Global, 2011.

[2] T. M. Choi and C. H. Chiu, "Mean-downside-risk and meanvariance newsvendor models: implications for sustainable fashion retailing," International Journal of Production Economics, vol. 135, no. 2, pp. 552-560, 2010.

[3] J. J. Spengler, "Vertical integration and antitrust policy," The Journal of Political Economy, vol. 58, no. 4, pp. 347-352, 1950.

[4] B. A. Pasternack, "Optimal pricing and return policies for perishable commodities," Marketing Science, vol. 4, no. 2, pp. 166-176, 1985.

[5] T. M. Choi, D. Li, H. Yan, and C. H. Chiu, "Channel coordination in supply chains with agents having mean-variance objectives," Omega, vol. 36, no. 4, pp. 565-576, 2008.

[6] G. P. Cachon and M. A. Lariviere, "Supply chain coordination with revenue-sharing contracts: strengths and limitations," Management Science, vol. 51, no. 1, pp. 30-44, 2005. 
[7] A. A. Tsay, S. Nahmias, and N. Agrawal, "Modeling supply chain contracts: a review," in International Series in Operations Research and Management Science, pp. 299-336, 1999.

[8] Z. Lian and A. Deshmukh, "Analysis of supply contracts with quantity flexibility," European Journal of Operational Research, vol. 196, no. 2, pp. 526-533, 2009.

[9] C. J. Corbett, D. Zhou, and C. S. Tang, "Designing supply contracts: contract type and information asymmetry," Management Science, vol. 50, no. 4, pp. 550-559, 2004.

[10] T. A. Taylor, "Supply chain coordination under channel rebates with sales effort effects," Management Science, vol. 48, no. 8, pp. 992-1007, 2002.

[11] W. K. Wong, J. Qi, and S. Y. S. Leung, "Coordinating supply chains with sales rebate contracts and vendor-managed inventory," International Journal of Production Economics, vol. 120, no. 1, pp. 151-161, 2009.

[12] G. P. Cachon, "Supply chain coordination with contracts," Handbooks in Operations Research and Management Science, vol. 11, no. 1, pp. 229-340, 2003.

[13] C. H. Chiu, T. M. Choi, H. T. Yeung, and Y.X. Zhao, "Sales rebate contracts in fashion supply chains," Mathematical Problems in Engineering, vol. 2012, Article ID 908408, 19 pages, 2012.

[14] J. D. Dana and K. E. Spier, "Revenue sharing and vertical control in the video rental industry," The Journal of Industrial Economics, vol. 49, no. 3, pp. 223-245, 2001.

[15] J. H. Mortimer, "Vertical contracts in the video rental industry," Review of Economic Studies, vol. 75, no. 1, pp. 165-199, 2008.

[16] E. Cao, C. Wan, and M. Lai, "Coordination of a supply chain with one manufacturer and multiple competing retailers under simultaneous demand and cost disruptions," International Journal of Production Economics, vol. 141, no. 1, pp. 425-433, 2013.

[17] D. Hu and Q. Li, "Supply chain coordination under revenuesharing contract with sales effort effect," in Proceedings of the International Conference on Computer and Management (CAMAN '11), pp. 1-4, May 2011.

[18] K. Chen and T. Xiao, "Ordering policy and coordination of a supply chain with two-period demand uncertainty," European Journal of Operational Research, vol. 215, no. 2, pp. 347-357, 2011.

[19] C. H. Chiu, T. M. Choi, and C. S. Tang, "Price, rebate, and returns supply contracts for coordinating supply chains with price-dependent demands," Production and Operations Management, vol. 20, no. 1, pp. 81-91, 2011.

[20] Y. He, X. Zhao, L. Zhao, and J. He, "Coordinating a supply chain with effort and price dependent stochastic demand," Applied Mathematical Modelling, vol. 33, no. 6, pp. 2777-2790, 2009.

[21] H. Krishnan, R. Kapuscinski, and D. A. Butz, "Coordinating contracts for decentralized supply chains with retailer promotional effort," Management Science, vol. 50, no. 1, pp. 48-63, 2004.

[22] H. Emmons and S. M. Gilbert, "Note. The role of returns policies in pricing and inventory decisions for catalogue goods," Management Science, vol. 44, no. 2, pp. 276-283, 1998.

[23] Y. Qin, H. Tang, and C. Guo, "Channel coordination and volume discounts with price-sensitive demand," International Journal of Production Economics, vol. 105, no. 1, pp. 43-53, 2007.

[24] H. M. Markowitz, Portfolio Selection: Efficient Diversification of Investments, 1959.

[25] P. C. Fishburn, "Mean-risk analysis with risk associated with below-target returns," The American Economic Review, vol. 67, no. 1, pp. 116-126, 1977.
[26] S. Choi and A. Ruszczyński, "A risk-averse newsvendor with law invariant coherent measures of risk," Operations Research Letters, vol. 36, no. 1, pp. 77-82, 2008.

[27] C. H. Chiu and T. M. Choi, "Optimal pricing and stocking decisions for newsvendor problem with value-at-risk consideration," IEEE Transactions on Systems, Man, and Cybernetics A, vol. 40, no. 5, pp. 1116-1119, 2010.

[28] J. Y. Gotoh and Y. Takano, "Newsvendor solutions via conditional value-at-risk minimization," European Journal of Operational Research, vol. 179, no. 1, pp. 80-96, 2007.

[29] Y. H. Chen, M. H. Xu, and Z. G. Zhang, "A risk-averse newsvendor model under the CVaR criterion," Operations Research, vol. 57, no. 4, pp. 1040-1044, 2009.

[30] K. S. Sundar, S. Narayanan, and D. Nagaraju, "Coordination in two level supply chain with price dependent demand," Applied Mathematical Sciences, vol. 6, no. 74, pp. 3687-3703, 2012.

[31] J.-M. Chen, H.-L. Cheng, and M.-C. Chien, "On channel coordination through revenue-sharing contracts with price and shelf-space dependent demand," Applied Mathematical Modelling, vol. 35, no. 10, pp. 4886-4901, 2011.

[32] F. J. Arcelus, S. Kumar, and G. Srinivasan, "Evaluating manufacturer's buyback policies in a single-period two-echelon framework under price-dependent stochastic demand," Omega, vol. 36, no. 5, pp. 808-824, 2008.

[33] V. Agrawal and S. Seshadri, "Impact of uncertainty and risk aversion on price and order quantity in the newsvendor problem," Manufacturing and Service Operations Management, vol. 2, no. 4, pp. 410-423, 2000.

[34] C.-H. Chiu, T.-M. Choi, and X. Li, "Supply chain coordination with risk sensitive retailer under target sales rebate," Automatica, vol. 47, no. 8, pp. 1617-1625, 2011.

[35] X. Gan, S. P. Sethi, and H. Yan, "Coordination of supply chains with risk-averse agents," Supply Chain Coordination under Uncertainty, vol. 3, no. 1, pp. 135-149, 2004.

[36] Y. Wei and T. M. Choi, "Mean-variance analysis of supply chains under wholesale pricing and profit sharing schemes," European Journal of Operational Research, vol. 204, no. 2, pp. 255-262, 2010. 


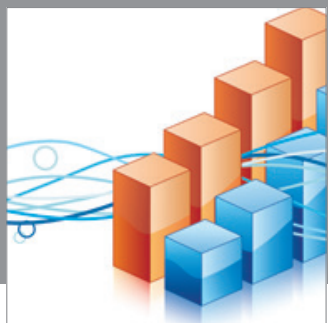

Advances in

Operations Research

mansans

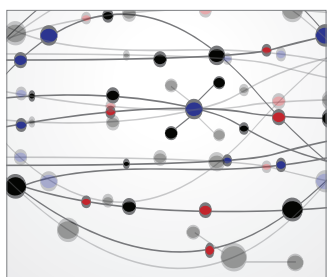

The Scientific World Journal
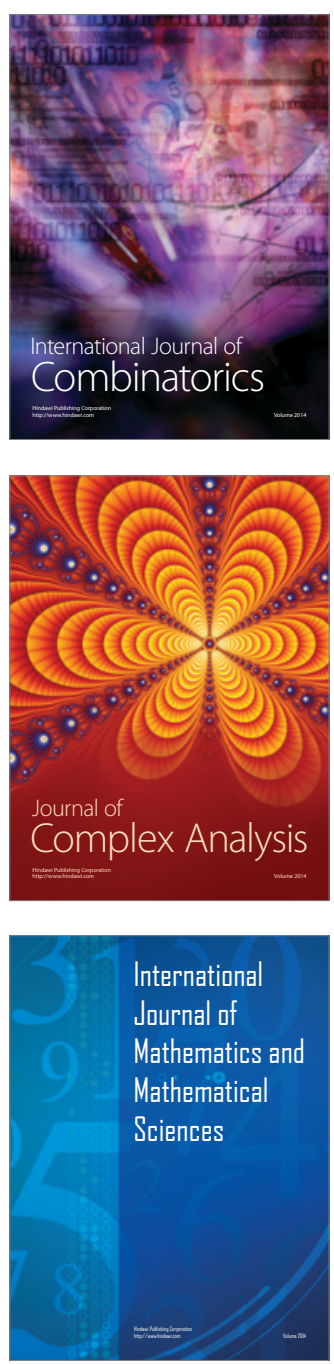
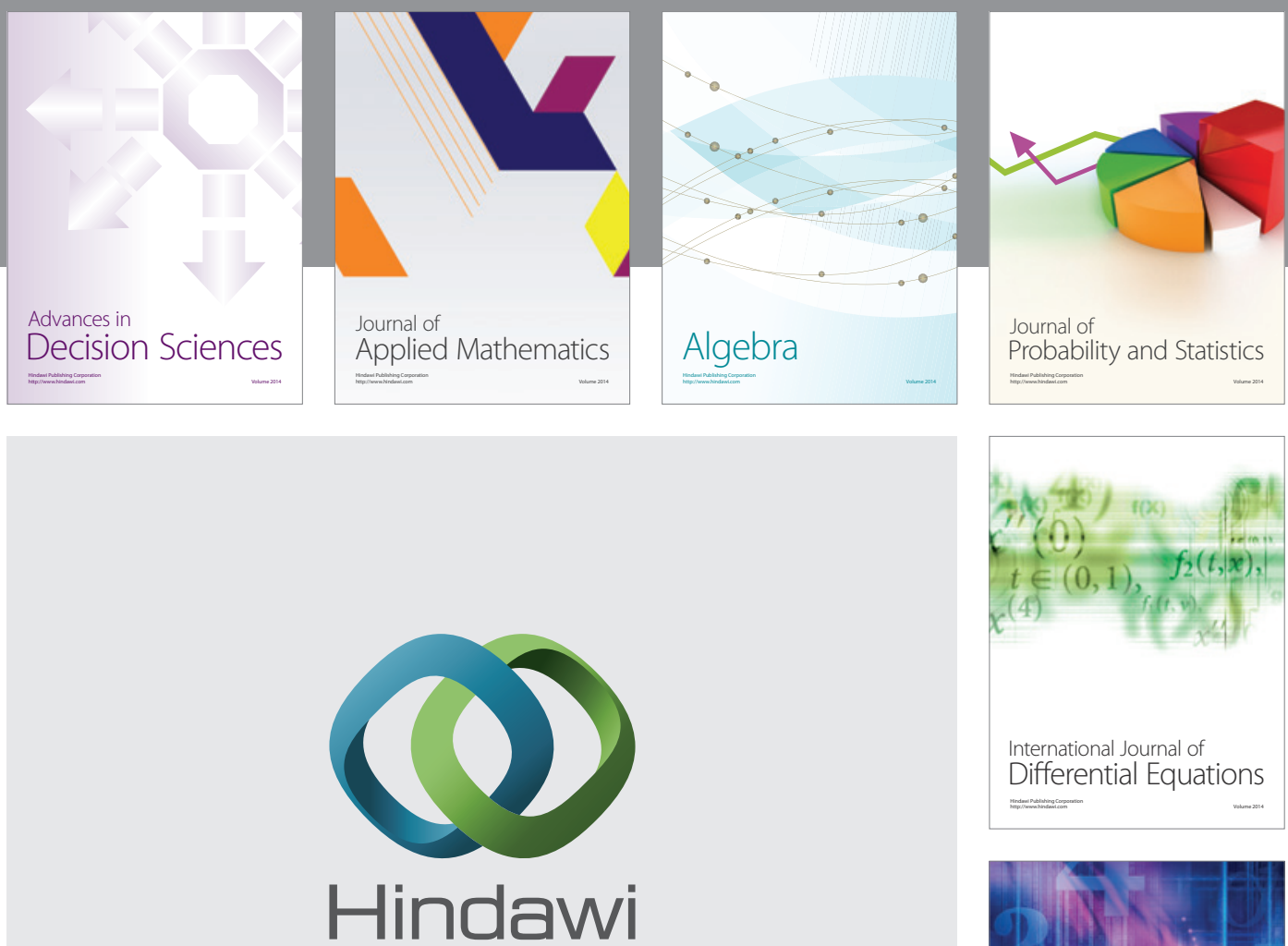

Submit your manuscripts at http://www.hindawi.com
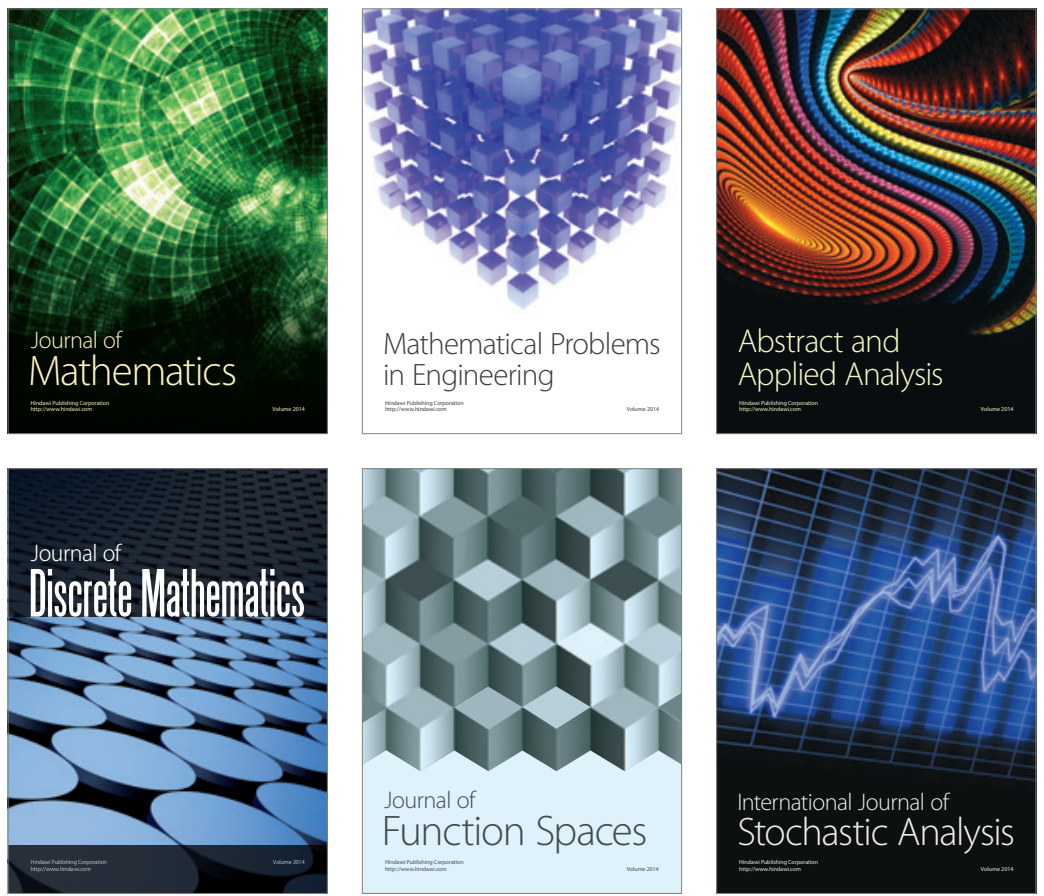

Journal of

Function Spaces

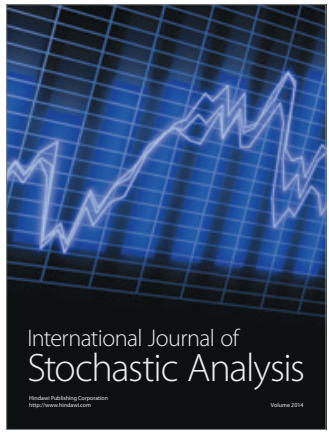

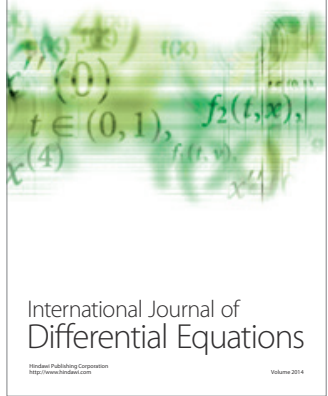
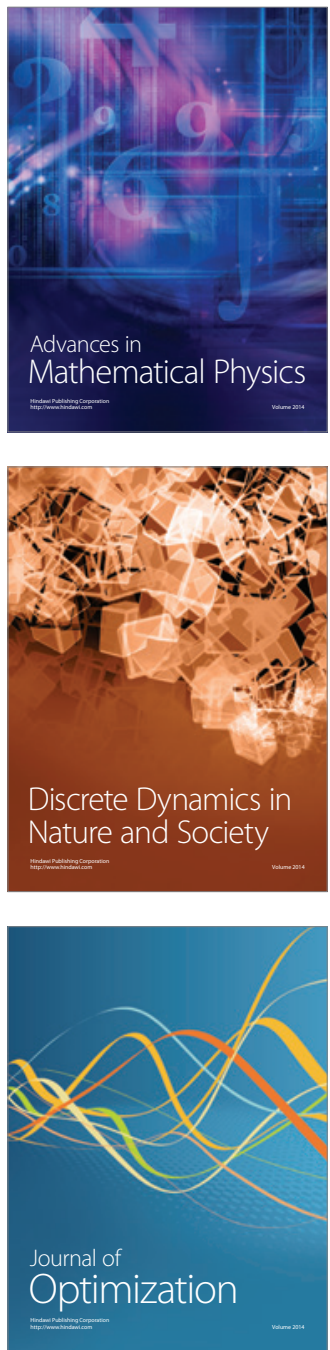